\title{
Contrasts in fitness, motor competence and physical activity among children involved in single or multiple sports
}

\author{
Kasper Salin ${ }^{1}$, Mikko Huhtiniemi ${ }^{1}$, Anthony Watt $^{2}$, Kaisu Mononen ${ }^{3}$, Timo Jaakkola ${ }^{1}$ \\ ${ }^{1}$ Faculty of Sport \& Health Sciences, University of Jyväskylä, Jyväskylä, Finland; ${ }^{2}$ College of Arts \& Education, Victoria \\ University, Melbourne, Australia; ${ }^{3}$ Research Institute for Olympic Sports, Jyväskylä, Finland
}

\begin{abstract}
Study aim: While there is wide debate around specialization in one sport, there is a lack of information about fitness levels and motor competence of children participating in single or multiple sports.

Material and methods: The study involved 358 fifth-grade children who participated in a set of health-related fitness and motor competence tests over two consecutive years. A subsample of children $(n=109)$ wore an accelerometer for seven consecutive days. The independent samples t-test and ANCOVA were used to compare differences between single and multi-sport participants in study variables and changes between baseline and follow-up.

Results: Multi-sport participants performed better in shuttle run (baseline/follow-up; $p=0.001 / p=0.006$ ), push-up $(p=0.006 / p=0.036)$, and five leap tests $(p=0.001 / p=0.009)$ in baseline than single sport participants among boys. Likewise, multi-sport participants showed significantly more improvement in the throwing and catching combination test between study years among boys $\mathrm{F}_{1,159}=3.570, p=0.030$. Among girls, no differences were found in any study variable between single and multi-sport participants.

Conclusions: From the perspective of fitness and motor competence tests, there are no arguments for participating in just one sport at an early age. Instead, multi-sport participants performed better than single sport participants in the majority of test variables.
\end{abstract}

\section{Keywords: Accelerometer - Physical fitness - Motor competence - Multi-sport - Single sport - Longitudinal}

\section{Introduction}

Participating in organized sports is an essential aspect of life for many children and adolescents. Kokko et al. [32] reported that approximately two-thirds of children and adolescents participated in sport club activities in many Western countries. For example, in Finland, organized sport is based on involvement in sports clubs rather than in sports academies or schools [20]. It has been acknowledged that competitive sport has emerged as a change of focus in youth sport from child-driven and recreational sport to adult-driven, highly structured organized sport that is more success and target oriented [3,33]. This change has also raised a debate whether young athletes should participate in only one sport or multiple sports [1]. Early engagement in single sport and involvement in competition before the age of 12 has been considered as early specialization [34].
In the junior sport field, there are many practitioners who believe that early specialization is the necessary path when developing elite athletes [43]. The contrasting approach is categorized as late specialization (or sampling) and involves young athletes engaging in multiple sport activities across childhood and early adolescence. Many practitioners follow the late specialization route and believe that it is essential for future success [14].

The issue of participating in just one sport during early childhood has sparked both positive and negative arguments. There are arguments that participating in just one sport is associated with success at the junior level [24], and it seems to be a prerequisite in some sports (e.g. figure skating and gymnastics) [14, 44]. Previous research has also indicated that participation in a single sport promotes higher focus on athletic achievement [21]. Counterarguments highlight the negative aspects of one sport focused training such as less emphasis on the "fun" aspects 
of activities [21], higher risk of injuries [16], increases in psychological stress or burnout [16], earlier drop-out [16], social isolation [38] or suppression of comprehensive motor skill development. This, in turn, may negatively influence the achievement of optimal performance later in the athlete's career [25]. In addition, participation in a single sport may not necessarily lead to success in the later athletic career, but instead is associated with many athletes increasing their physical inactivity [42]. Recently, it was found that participation in a single sport does not necessarily have superior task related performance (e.g. better fitness test results) when compared to those who play several sports [31].

However, participating in multiple sports has been highlighted to facilitate a repertoire of fundamental sports skills [14]. Apart from physical development, other benefits are gained from participation in multiple sports [42]. Engaging in a wide range of sports activities as a young person will promote diverse relationships and experiences and promote physical activity options in adulthood [42]. Additionally, this can foster children's intrinsic motivation, provide diverse social experiences and constrain the tendency to be drawn into "specific sports culture" [42]. Research has demonstrated that young athletes may benefit from participation in multiple sports because it has the capacity to foster a lifelong engagement in physical activity, provide a variety of enjoyable social experiences, and lead to a lower frequency of injuries, dropouts and mental problems [15]. Previous studies have shown that participation in multiple sports is more likely to promote a task climate that will nurture children's interest in sport and promote intrinsic motivation [42]. In addition, multi-sport engagement provides variability in the stimuli for muscular and nervous systems across childhood and adolescence. Boys (aged 10-12) participating in multiple sports perform better in tests measuring maximal static and explosive strength (standing broad jump), strength test (knee push-up) and a test measuring speed and agility (10 x 5-meter shuttle run) than boys participating in just one sport [22]. However, in flexibility and cardiovascular endurance, there were no differences between single and multi-sport participants. It has also been reported that boys usually outperform girls in fitness tests, except mobility tests [12]. It is worth noting that similar differences also exist at an earlier age [37].

Physical activity during leisure time has demonstrated a strong association with health-related fitness [10], which is typically formulated as an outcome of cardiorespiratory endurance, muscular endurance, muscular strength, body composition, and flexibility [9]. Furthermore, individuals with higher levels of health-related fitness have a lower risk for cardiovascular mortality [19] and morbidity [30]. In addition, health-related fitness is associated with skeletal [54] and mental health [51]. Motor competence is also an important factor to promote and sustain engagement with physical activities during childhood and adolescence [47] and is mediated by a relationship with proficiency in fundamental motor skills (i.e. object control and locomotor skills). In addition to perceived competence, enjoyment is a contributing factor to maintain the participation. Also, drop-out may be partly explained by specializing in one sport [17]. Previous research showed that among 10-12 year old boys, multiple sports participants performed better in gross motor coordination tests (motor quotient) than single sport participants [22]. Without adequate levels of motor competence, youth are less likely to be physically fit [50]. In addition, higher motor competence has been shown to be associated with lower levels of central obesity [26].

While there is evidence related to competitive success in youth level between single and multi-sport participants, there is a gap in research investigating differences in health-related physical fitness, motor competence and moderate to vigorous physical activity between single or multi-sport participants. Therefore, the aim of this study was to investigate differences between single and multisport participants' fitness and motor competence test scores at baseline and follow-up and over two consecutive years. In addition, differences between boys and girls in health-related fitness, motor competence, and physical activity were analysed.

\section{Material and methods}

\section{Participants}

Data were collected from 37 different classes across 17 socio-demographically representative Finnish schools in September 2017 and September 2018. In total, 1148 children (583 girls, 565 boys) aged 11-12 years at baseline $(\mathrm{M}=11.3, \mathrm{SD}=0.3)$ participated in the study. From this group, 715 participants were also involved in fitness tests in both years and from a subsample of 550 participants, valid accelerometer data were collected. From 550 participants, 247 participants had valid accelerometer data from both years. Participants' stature was assessed to the nearest $0.1 \mathrm{~cm}$ using portable measuring equipment. Body mass was measured to the nearest $0.1 \mathrm{~kg}$ using a scale calibrated for barefooted children in light clothing. For each participant, BMI was calculated, and transformed to a Zscore [11]. Mean BMI at baseline was 18.7 (SD 2.8) (girls 18.8 [2.8], boys 18.9 [2.7)].

\section{Measures, design and procedures}

The participants completed self-report questionnaires at baseline and follow-up regarding involvement in organized sports. Researchers collected all questionnaire data and clarified questions if children did not understand 
them. The participants were asked the number of sports they practised. Sport club participation was assessed with the structured question "are you a participating member of a sports club?" with answer options: yes, regularly; yes, now and then; not at the moment, but I used to; and no, and I have never been. Those who answered "yes, regularly" were considered as sport club participants. The answers were categorized into several groups including single sport and multi-sport participants (participants who had either one sport or multiple sports at both baseline and follow-up). Consequently, the final sample comprised 358 single and multi-sport participants who had valid fitness test data from baseline and follow-up. In addition, valid accelerometer data were obtained from 109 participants.

\section{Ethics statement}

Ethical approval was obtained from the University of Jyväskylä ethical committee. Written parental consent and child assent to complete the study were obtained before participation.

\section{Physical fitness tests and motor competency tests}

The curl-up test assesses abdominal strength [28] and has been found to be a reliable test for use with children and adolescents [45]. In the curl-up test, the participant performed as many curl-ups as possible with a maximum set at 75 at the pace of a dictated pre-recorded sound signal. The participant started the test in a lying position, with knees bent at 100 degrees, heels and feet on the mat and arms straight, parallel to the trunk. Participants kept their arms extended and using the abdominal muscles, they slid their fingertips along the mat $(8 \mathrm{~cm})$ until they reached the marker. The test ended due to stopping to rest, fatigue, improper form or the end of the sound marker. The participant conducted the test once and the total number of correctly performed curl-ups was recorded [40].

The push-up test has been recommended for assessing upper body strength because there are no requirements for equipment, several students can be tested at the same time, and most students can perform at least one push-up [13]. The push-up test has been found to be a reliable method for measuring upper body strength within youth [48]. The participant completed as many defined form $90^{\circ}$ degree push-ups as possible in 60 seconds and the number of correctly performed push-ups was counted. Push-ups were done under the supervision of researchers, who decided whether or not the performance was accepted. Girls performed the test with a knee push-up test. The participants performed the test once.

The assessment of cardiovascular fitness involved the use of the 20-meter shuttle run test [36]. Participants continuously cover a shuttle distance of 20 meters between two lines at the pace dictated by a pre-recorded sound signal. The signal gets faster every minute. Participants continue until they can no longer maintain the current pace. The number of completed shuttles was used as a variable in the analyses [34]. The participants had one try to perform the test.

The throwing and catching combination test has been developed in Finland for children aged 11-15 [28] and it is reliable for measuring manipulative skills and upper body strength for children without special needs [28]. Each participant throws a tennis ball 20 times at a square of 1.5 meters $\times 1.5$ meters (bottom of the square at the height of $90 \mathrm{~cm}$ ) and moves forward to catch the ball after one bounce from the floor. The distance for throwing was seven meters for fifth-grade girls and eight meters for boys [28]. If the participant failed to catch the ball, the participant proceeded to the next throw and continued until 20 throws had been performed. There was no time limit to perform the test. Successful throw-catches were counted with a maximum score of 20 . The participants had one try to perform the test.

The five leaps test was used as a measure for muscular strength of lower limbs and locomotor skills. This test is widely used and reliable for measuring muscular strength of the lower limbs and leaping skills [6]. A participant takes five leaps, starting and finishing with both legs in a parallel position. The total length of the five leaps is measured in centimetres from the starting position to the heel of the leg furthest back upon landing. Participants had a possibility to perform the leap sequence twice and the better result was recorded in the result sheet. All tests were performed under the supervision of research staff members during a regular physical education lesson.

\section{Moderate to vigorous physical activity}

A subsample of 589 children was recruited in 2017, and accelerometers were provided to each of these participants in both study years. Analyses of moderate-to-vigorous physical activity were restricted to 109 participants who provided at least three days (two week days + one weekend day) of valid accelerometer data in both study years. Children were fitted with a wGT3X-BT Actigraph accelerometer (Pensacola, FL) by trained researchers at the beginning of the data collection period. Participants were asked to wear the accelerometer for seven consecutive days (except for sleep time and water-based activities) on their right hip attached via an elastic belt. The epoch length was set at 15 seconds and data were processed using the Actilife Lifestyle monitoring System, version 6.12.1. Non-wear time was defined as $30 \mathrm{~min}$ of consecutive zeros. Three-day measurement has proven to be a reliable method when investigating physical activity [39]. A valid day was defined as recording at least 500 min of measured wear time between 07:00 and 23:00. In previous studies, it has been demonstrated that at least 360 minutes should be measured for a valid day [7]. To 
avoid possible bias in physical activity levels, children who provided three valid days of accelerometer data were compared with those who provided four or more days. No differences between moderate-to-vigorous physical activity levels were found. Standard cut-points were used to define the mean daily percentage of time spent at various intensities: sedentary (0-100 counts per minute [CPM]), light (101-2295 CPM) and moderate-to-vigorous physical activity (>2295 CPM) [7].

\section{Statistical analyses}

Descriptive statistics of the participants are shown in Table 1. The following continuous variables were not approximately normally distributed: shuttle run test in 2017 and 2018 among girls and five leaps test among boys in 2018. Other variables were normally distributed. To determine whether there were differences in study variables between single and multi-sport participants, the independent samples $t$-test was used. Cohen's $d$ was used to calculate the effect size. To examine the mean differences between single and multi-sport participants' fitness test and motor competence scores, we used a repeated measures analysis of covariance (ANCOVA), where baseline scores and sex were included as covariates. Bonferroni correction was used. The between-subjects factor in the analysis was based on the variable of sport participation classification (single/multiple sport participation). For all variables, all assumptions for conducting repeated measures ANCOVA were met: there was homogeneity of variance (assessed as Levene's test, $p=0.112-0.841$ ) and no outliers were detected. Eta squared is reported for all the continuous variables as a measure of effect size. All statistical analyses were performed with IBM SPSS Statistics 24.

\section{Results}

Demographics and distribution of participants in single and multi-sport categories are presented in Table 1. Likewise, number of sports participated in in 2017 and 2018 are presented in Table 1.

Differences in test scores at baseline and follow-up measurement points

Results (mean, SD) between different sport participation groups are reported in Table 2. Among boys, multi-sport participants showed higher test scores in shuttle run (baseline/follow-up; $p=0.001 / p=0.006$ ), push-up $(p=0.006 / p=0.036)$, and five leap tests $(p=0.001 / p=0.009)$ than single sport participants at baseline and follow-up measurement points. In addition, multi-sport participants performed better in the curl-up test at baseline than single sport participants $(p=0.021)$. Among girls, no differences were found between different sport participants.

Between boys and girls in single sport participants group, there was a significant difference in push-ups

Table 1. Demographics (mean and SD) of sport participants in the baseline $(n=358)$, and moderate to vigorous physical activity between single and multi-sport participants $(n=109)$

\begin{tabular}{lcc}
\hline & Single-sport participants $(n=176)$ & Multi-sport participants $(n=97)$ \\
\hline Age [years] & $11.27(0.30)$ & $11.21(0.33)$ \\
Height $[\mathrm{cm}]$ & $148.95(6.96)$ & $146.79(6.24)$ \\
Weight & $41.76(7.58)$ & $39.21(6.5)$ \\
Body Mass Index $\left.\left[\mathrm{kg} / \mathrm{m}^{2}\right]\right)$ & $18.72(2.53)$ & $18.12(2.34)$ \\
No of sports participated & $1(0)$ & $2.45(0.69)$ \\
in 2017 & $1(0)$ & $2.24(0.56)$ \\
No of sports participated & & \\
in 2018 & &
\end{tabular}
in 2018

Moderate to vigorous physical activity

\begin{tabular}{lcccc}
\hline & Single sport participants $(n=68)$ & Multi-sport participants $(n=41)$ & $\mathrm{p}$ & Cohen's $d$ \\
MVPA* (mins) 2017 & $60.9(22.7)$ & $68.7(24.1)$ & 0.119 & 0.33 \\
MVPA (mins) 2018 & $60.0(21.5)$ & $64.9(18.3)$ & 0.262 & 0.24 \\
\hline & Boys & Girls & \\
\hline MVPA (mins) 2017 & $69.9(22.2)$ & $63.3(24.6)$ & $\mathbf{0 . 0 4 4}$ & 0.28 \\
MVPA (mins) 2018 & $65.8(22.2)$ & $58.8(19.4)$ & $\mathbf{0 . 0 4 5}$ & 0.33 \\
\hline
\end{tabular}

* - moderate-to-vigorous physical activity. 
Table 2. Means, standard deviations, and main effects for group outcome measures $(n=168)$ of motor competence and fitness test scores in 2017 and 2018, between different sport participants

\begin{tabular}{|c|c|c|c|c|}
\hline & $\begin{array}{l}\text { Single sport participant boys } \\
(n=103)\end{array}$ & $\begin{array}{l}\text { Multi-sport participants boys } \\
\qquad(n=65)\end{array}$ & $\mathrm{p}$ & Cohen's $d$ \\
\hline Shuttle run test $2017^{1}$ & $41.9(19.7)$ & $53.1(19.8)$ & 0.003 & 0.56 \\
\hline Shuttle run test $2018^{1}$ & $44.5(20.9)$ & $56.3(22.4)$ & 0.004 & 0.54 \\
\hline 5 leaps test 2017 & $7.8(0.9)$ & $8.2(0.7)$ & 0.036 & 0.5 \\
\hline 5 leaps test 2018 & $8.3(1.1)$ & $8.7(0.7)$ & 0.006 & 0.44 \\
\hline Curl-up 2017 & $37.5(20.5)$ & $46.7(21.9)$ & 0.021 & 0.43 \\
\hline Curl-up 2018 & $42.8(21.6)$ & $50.2(20.6)$ & 0.060 & 0.35 \\
\hline Push-up 2017 & $18.4(10.7)$ & $23.8(11.3)$ & 0.009 & 0.49 \\
\hline Push-up 2018 & $15.8(11.6)$ & $24.3(14.7)$ & 0.001 & 0.64 \\
\hline Throwing catching test 2017 & $13.0(4.3)$ & $12.7(4.9)$ & 0.711 & 0.06 \\
\hline \multirow[t]{2}{*}{ Throwing catching test 2018} & $13.5(4.9)$ & $15.2(4.0)$ & 0.051 & 0.38 \\
\hline & $\begin{array}{l}\text { Single sport participant girls } \\
\qquad(n=124)\end{array}$ & $\begin{array}{l}\text { Multi-sport participants girls } \\
\qquad(n=66)\end{array}$ & $\mathrm{p}$ & Cohen's $d$ \\
\hline Shuttle run test 2017 & $36.0(14.4)$ & $38.8(16.4)$ & 0.274 & 0.18 \\
\hline Shuttle run test 2018 & $40.7(16.2)$ & $46.9(19.9)$ & 0.059 & 0.34 \\
\hline 5 leaps test 2017 & $7.9(0.8)$ & $7.8(1.0)$ & 0.846 & 0.11 \\
\hline 5 leaps test 2018 & $8.2(0.8)$ & $8.5(0.9)$ & 0.184 & 0.35 \\
\hline Curl-up 2017 & $44.0(22.5)$ & $45.2(24.0)$ & 0.780 & 0.05 \\
\hline Curl-up 2018 & $44.3(20.4)$ & $49.0(21.7)$ & 0.192 & 0.22 \\
\hline Push-up 2017 & $26.8(11.2)$ & $28.9(10.2)$ & 0.273 & 0.19 \\
\hline Push-up 2018 & $24.3(12.0)$ & $26.4(13.3)$ & 0.334 & 0.16 \\
\hline Throwing-catching test 2017 & $10.3(4.7)$ & $10.0(5.1)$ & 0.756 & 0.06 \\
\hline Throwing-catching test 2018 & $13.5(3.8)$ & $13.4(4.8)$ & 0.896 & 0.02 \\
\hline
\end{tabular}

1 - number of shuttles.

$(p<0.001)$ at baseline and follow-up, and in the shuttle run $(p=0.027)$, curl-up $(p=0.05)$, and throwing and catching combination tests $(p<0.001)$ at baseline, boys having higher scores in the shuttle run test and the throwing and catching combination test, while girls had higher scores in the push-up and curl-up tests. Among multi-sport participants, boys had higher scores in the throwing and catching test $(p=0.013)$ at baseline and in the shuttle run test in both years $(p<0.001-0.032)$. Girls performed better in the push-up test $(p=0.022)$.

\section{Changes in test scores between baseline and follow-up}

Among boys, multi-sport participants had larger increases in throwing and catching combination test score than single-sports participants, $\mathrm{F}_{1,159}=3.570, p=0.030$. Among girls, there were no differences between single and multi-sport participants in change in scores. Among single sport participants, boys had smaller decreases in push-up test scores, $\mathrm{F}_{1,173}=5.011, p=0.026$, than girls, and girls had a larger increase in throwing and catching combination scores than boys, $\mathrm{F}_{1,173}=6.930, p=0.009$.

\section{Physical activity}

A total of 109 children had valid accelerometer data from both years. Results are presented in Table 1. Overall, no differences were found between single and multi-sport participation groups at baseline or follow-up in moderateto-vigorous physical activity. However, boys had higher scores for moderate-to-vigorous physical activity at baseline $(p=0.044)$ and follow-up $(p=0.045)$ than girls. Furthermore, changes in moderate-to-vigorous physical activity between baseline and follow-up were not statistically 
significantly different between single and multi-sport participation groups or between boys and girls.

\section{Discussion}

The purposes of this study were to investigate differences between single and multi-sport participants' fitness test and motor competence a) test scores in baseline and follow-up and b) test score changes between two consecutive years. Additionally, moderate to vigorous physical activity was compared between single and multi-sport participants at baseline and follow-up. In addition, differences between boys and girls in health-related fitness, motor competence, and physical activity were analysed.

\section{Differences in fitness and motor competence tests at baseline and follow-up}

Overall, those who participated in multiple sports performed better in the majority of the fitness test and motor competence variables at baseline and follow-up. Differences found in this study were in line with previous research [22], indicating that sampling various sports strengthens the development of fitness and motor competence. It has been stated previously that participation in one sport does not appear to improve the task-related performance outcomes of athletes when compared to multiple sport athletes [31]. In this study, better cardiovascular and muscular fitness was one outcome of participating in multiple sports, but it should be noted that it is not the only benefit of multiple sports participation. According to Côte [14], participating in multiple sports exposes children to a greater number of physical, cognitive, affective, and psycho-social environments than participating only in a single sport. The result demonstrating that participation in several sports was more strongly associated with muscular fitness is an important finding because research has shown that better muscular fitness may decrease children's susceptibility to sports-related injuries [18]. In addition, it has been found that children's muscular fitness levels track into adulthood and are linked to future cardiovascular disease risk [23].

Differences in fitness and motor competence test scores between boys and girls might be a result of variation in the types of sports in which the children participated. Whilst among boys, ball games (e.g. football) are more favoured, among girls, aesthetic sports such as gymnastics and dance are preferred [41]. In these sports, physical requirements are different and may explain the difference between boys and girls in fitness test scores. In a previous study [46], ball game participants scored higher in shuttle run and sprint tests, while gymnastics participants performed better in sit-ups, even though the results were not statistically significant when the training volume was considered in the analysis. In addition, it should be noted that motives for participation in certain sports are different. For boys, performance motives are more important compared to girls, and this may drive boys to apply more effort during the training [29]. At the same time, girls participate in sports predominantly because of social and health reasons [29] and are more prone to seek enjoyment and feelings of competence [4]. In addition, sex may influence the experience of youth sport specialization, as boys and girls may differ in achieving developmental milestones [31].

\section{Changes in test scores between baseline and follow-up}

In this study, differences were found between multisport participants and single sport participants in change in scores for boys on the throwing and catching test. It has been reported that object control skills in childhood are positively associated with adolescent moderate-to-vigorous physical activity [2]. Participating in multiple sports appeared to support the maintenance of a higher level of motor competence, since among single sport participants the motor competence change score was lower. These differences may indicate that participating in multiple sports develops motor skills in a more versatile way and this explains the difference in change in scores between single and multi-sport participants.

\section{Physical activity at baseline and follow-up}

Boys had higher levels of moderate-to-vigorous physical activity than girls at both baseline and follow-up. This is in line with previous studies highlighting the difference in physical activity between boys and girls to reveal higher levels for boys in early adolescence [52].

It is also notable that participation in one sport, in this sample, did not mean lower levels of moderate-to-vigorous physical activity time despite practising just one sport. It should be noted that daily moderate-to-vigorous physical activity is facilitated by a range of physical activities apart from participation in organized sport [49]. While physical activity levels did not differ between single and multi-sport participants, it should be highlighted that participation in organized sport does not mean that recommended guidelines for physical activity are met. In previous studies it has been shown that fewer than one-fourth of youth sport participants obtained the recommended 60 minutes of moderate-to-vigorous physical activity during practice [35]. Hence, it should be kept in mind that the remainder comes from physical education, unstructured play, and general human movement. While the results of this study favours participation in multiple sports, it should be kept in mind that an excessive amount of training may lead to negative consequences such as fatigue, sleep disturbances, chronic muscle pain and performance decline [8]. 


\section{Strengths and limitations}

In this study, the sample size for health-related fitness and motor competence tests was high enough to compare participants with different participation status between the study years. In addition, the accelerometer data were sufficient to allow comparison of physical activity levels between single and multi-sport participants. It is also not known how many months per year children have spent in their sport clubs. At the age of 12, children are usually in the developmental phase of their athletic career and typically participate in their sport across the entire calendar year [55]. While the number of training sessions was not reported, moderate-to-vigorous physical activity time was reported for the subsample, and intensity of participation was found to be similar within the different sports. Furthermore, the competition level of participants was not assessed. In most sports the competition level is still regional, but for certain sports (e.g. gymnastics) there may already be national level competitions. Hence, the competitive seriousness of the participation may vary between sports. Additionally, socioeconomic status was not measured in this study, which limited the capacity to contrast the current results with previous research that reported that among girls there are associations between socioeconomic status and physical fitness variables [53]. Motor competence was measured only via throwing and catching, and hence it does not give a complete overview of motor competencies since no kicking, skipping etc. were measured. However, the five leaps test, which can be seen as a part of lower body competence, was measured in this study. In the future, longer follow-up studies of single and multiple sport participants could be done. Also, tracking the objective physical activity levels of single and multiple organized sport participants warrants specific investigation.

\section{Conclusions}

The results from this study showed that participating in multiple sports was related to higher performance among boys in fitness and motor competence tests at the age of 11 and 12. This should serve as an impetus to encourage children to play multiple sports rather than concentrating on just one sport. In a recent study, it was found that participating in multiple activities was associated with higher academic achievement in addition to typical cardiovascular fitness benefits [27]. While there was the support of higher physical performance among multi-sport participants, a critical perspective to also consider is that involvement in multiple sports is associated with continuing sport participation later in adolescence [5]. Also, coaches should keep in mind the negative aspects of sports such as overtraining and emotional exhaustion, which may lead to earlier drop-out. Hence, in sport clubs it should be kept in mind that engaging children in regular physical activity as long as possible should be the most important objective.

\section{Conflict of interest: Authors state no conflict of interest.}

\section{References}

1. Baker J., Cobley S., Fraser-Thomas J. (2009) What do we know about early sport specialization? Not much! High Ability Stud., 20(1): 77-89. DOI: 10.1080/13598130902860507

2. Barnett L., van Beurden E., Morgan P.J., Brooks L.O., Beard J.R. (2009) Childhood motors skill proficiency as a predictor of adolescent physical activity. J. Adolesc. Health, 44(3): 252-259. DOI: 10.1016/j. jadohealth.2008.07.004.

3. Bean C.N., Frontier M.P., Chima K. (2014) Understanding how organized youth sport may be harming individual players within the family unit: a literature review. Int. J. Environ. Res. Public Health, 11(10): 10226-10268.

4. Biddle S.J., Whitehead S.H., O'Donovan T.M., Nevil M.E. (2005) Correlates of participation in physical activity for adolescent girls: A systematic review of recent literature. J. Phys. Act. Health, 2: 423-434. DOI: 10.1123/ jpah.2.4.423.

5. Blomqvist M., Mononen K., Koski P., Kokko S. (2018) Urheilu ja seuraharrastaminen [Sport and sport club participation]. In Kokko S. and Martin L. (eds) Lasten ja nuorten liikuntakäyttäytyminen Suomessa, LIITU-tutkimuksen tuloksia 2018. [Physical activity behaviour of children and adolescents in Finland, results from LIITUstudy 2018]. Publications of the National Sports Council. 201 adapting to include 8. 47-56.

6. Bouhlel E., Bouhlel, H., Chelly M.S., Tabka Z. (2006) Relationship between maximal anaerobic power measured by force-velocity test and performance in the counter movement jump and in the 5-jump test in moderately trained boys. Sci. Sports, 21(1): 1-7.

7. Cain K.L., Salli J.F., Conway T.L., Van Dyck D., Calhoon L. (2013) Using accelerometers in youth physical activity studies: a review of methods. J. Phys. Act. Health, 10: 437-450. DOI: 10.1123/jpah.10.3.437.

8. Carter C.W., Micheli L.J. (2011) Training the child athlete for prevention, health promotion, and performance: How much is enough, how much is too much? Clin. Sports Med., 30(4): 679-690. DOI: 10.1016/j.csm.2011.06.004.

9. Caspersen C.J., Powell K.E., Christenson G.M. (1985) Physical activity, exercise, and physical fitness: definitions and distinctions for health-related research. Public Health Rep., 100(2): 126-131. 
10. Chen W., Hammond-Bennett A., Hypnar A., Mason S. (2018) Health-related physical fitness and physical activity in elementary school students. BMC Public Health, 18: 195. DOI: 10.1186/s12889-018-5107-4.

11. Cole T. J., Bellizzi M.C., Flegal K.M., Dietz, W. H. (2007) Establishing a standard definition for child overweight and obesity worldwide: international survey. $B M J$, 320:1240. DOI: 10.1136/bmj.320.7244.1240.

12. Colley R.C., Clarke J., Doyon C.Y., Lang J.J., Timmons B.W. Tremblay M.S. (2019) Trends in physical fitness among Canadian children and youth. Statistics Canada, Catalogue, 30(10): 3-13. DOI: 10.25318/82-003 -x201901000001-eng.

13. Cooper Institute for Aerobics Research. (1999) FITNESSGRAM test administration manual. Champaign, IL: Human Kinetics.

14. Côté J., Lidor R., Hackfort D. (2009) ISSP position stand: To sample or to specialize? Seven postulates about youth sport activities that lead to continued participation and elite performance. Int. J. Sports Exerc. Psychol., 7(1): 7-17. DOI: 10.1080/1612197X.2009.9671889.

15. Côté J., Horton S., MacDonald D., Wilkes S. (2009) The benefits of sampling sports during childhood. Phys. Health Educ. J., 74(4): 6-11.

16. DiFiori J.P., Benjamin H.J., Brenner J.S., Gregory A., Jayanthi N., Landry G.L., Luke A. (2014) Overuse injuries and burnout in youth sports: a position statement form the American Medical Society for Sports Medicine. Br. J. Sport Med., 48: 287-288. DOI: 10.1136/bjsports2013-093299.

17. Eime R.M., Casey M.M., Harvey J.T., Charity M.J., Young J.A., Payne W.R. (2015) Participation in modified sports programs: a longitudinal study of children's transition to club sport competition. BMC Public Health, 15(1): 649. DOI: 10.1186/s12889-015-2012-y.

18. Faigenbaum A.D., Myer G.D. (2010) Resistance training among young athletes: safety, efficacy and injury prevention effects. Br. J. Sports Med., 44(1): 56-63.

19. Fogelholm M. (2010). Physical activity, fitness and fatness: relations to mortality, morbidity and disease risk factors. A systematic review. Obes. Rev., 11(3): 202-221. DOI: 10.1111/j.1467-789X.2009.00653.x.

20. Forsman H., Blomqvist M., Davids K., Konttinen, N., Liukkonen J. (2016) The role of sport-specific play and practice during childhood in the development of adolescent Finnish team sport athletes. Int. J. Sports Sci. Coaching, 11(1): 69-77. DOI: 10.1177/1747954115624816.

21. Feeley B.T., Agel J., LaPrade R.F. (2016) When it is too early for single sport specialization? Am. J. Sport Med., 44(1): 234-241. DOI: 10.1177/0363546515576899.

22. Fransen J., Pion J., Vendenriessche J., Vandorpe B., Vaeyens R., Lenoir M., Philippaerts R.M. (2012) Differences in physical fitness and gross motor coordination in boys aged 6-12 years specializing in one versus sampling more than one sport. J. Sport Sci., 30(4): 379-386. DOI: 10.1080/02640414.2011.642808.

23. Grøntved A., Ried-Larsen M., Møller N.C., Kristensen P.L. Froberg K., Brage S., Andersen L.B. (2015) Muscle strength in youth and cardiovascular risk in young adulthood (the European Youth Heart Study). Br. J. Sports Med., 49(2): 90-94. DOI: 10.1136/bjsports2012-091907.

24. Güllich A., Emrich E. (2014) Considering long-term sustainability in the development of world class success. Eur. J. Sport Sci., 14(suppl.1): S383-S397. DOI: 10.1080/17461391.2012.706320.

25. Hall R., Foss K.B., Hewett T.E., Myer G.D. (2015) Sport specialization's association with an increased risk of developing anterior knee pain in adolescent female athletes. $J$. Sport Rehabil., 24(1): 31-35. DOI: 10.1123/jsr.2013-0101.

26. Henrique R.S., Stodden D.F., Fransen J., Feitoza A.H. Ré, A.H., Martins C.M., dos Prazeras T.M.P., Cattuzzo M.T. (2020) Is motor competence associated with the risk of central obesity in preschoolers? Am. J. Hum. Biol., 32(3): e23364. DOI: 10.1002/ajhb.23364.

27. Ishihara T., Nakajima T., Yamatsu K., Okita K., Sagawa M. Morita N. (2020) Relationship of participation in specific sports to academic performance in adolescents: A 2-year longitudinal study. Scand. J. Med. Sci. Sport, DOI: 10.1111/sms.13703.

28. Jaakkola T., Sääkslahti A., Liukkonen J., Iivonen S. (2012) Peruskoululaisten fyysisen toimintakyvyn seurantajärjestelmä. Jyväskylä: University of Jyväskylä.

29. Kalman M., Madarasova Geckova A.M., Hamrik Z., Kopčáková J., Iannotti R.J., Dankulincová Veselská Z. (2015) Motives for physical activity among adolescents in the Czech and Slovak Republics. Cent. Eur. J. Public Health, 23: S78-S82. DOI: 10.21101/cejph.a4176.

30. Kaminsky L.A., Arena R., Beckie T.M., Brubaker P.H., Church T.S., Forman D.E., Franklin B.A., Gulati M., Lavie C.J., Myers J., Patel M.J., Piña I.L., Weintraub W.S., Williams M.A. (2013) The importance of cardiorespiratory fitness in the United States: The need of a national registry. A policy statement from the American Heart Association. Circ., 127(5): 652-662. DOI: 10.1161/ CIR.0b013e31827ee100.

31. Kliethermes S.A., Nagle K., Côte J., Malina R.M., Faigenbaum A., Watson A., Feeley B., Marshall Ss.W., LaBella C.R., Herman D.C., Tenforde A., Beutler A.I., Jayanthi N. (2019) Impact of youth sports specialization on career and task-specific athletic performance: a systematic review following the American Medical Society for Sport Medicine (AMSSM) Collaborative Research Network's 2019 Youth Early Sport Specialisation Summit. Br. J. Sport Med., 54(4): 221-230. DOI: 10.1136/ bjsports-2019-101365. 
32. Kokko S., Martin L., Geidne S., Van Hoye A., Lane A., Meganck J., Scheeder J., Seghers J., Villberg J., Kudlacek M., Badura P., Mononen K., Blomqvist M., De Clerq B., Koski P. (2018) Does sports club participation contribute to physical activity among children and adolescents? A comparison across six European countries. Scand. J. Public Health, DOI: 10.1177/1403494818786110.

33. Konttinen N., Kallinen V., Mononen K., Tolvanen A., Lochbaum M. (2019) Sports club participation impact on motor competencies, dispositional goal orientations, and perceptions of school-based physical education among Finnish third-grade children. Sporto Mosklas/Sports Sci., 95: 3-11.

34. LaPrade R.F., Agel L., Baker J., Brenner J.S., Cordasco F.A., Côte J., Engebretsen L., Feeley B.T., Gould D., Hainline B., Hewett T.E., Jayanthi N., Kocher M.S., Myer G.D., Nissen C.W., Philippon M.J., Provencher M.T. (2016) AOSSM early sport specialization consensus statement. Orthop. J. Sports Med., 4(4): 2325967116644241.

35. Leek D., Carlson J.A., Cain K.L., Henrichon S., Rosenberg D., Patrick K., Sallis F. (2011) Physical activity during youth sports practices. Arch. Pediatr. Adolesc. Med., 165(4): 294-299. DOI: 10.1001/archpediatrics.2010.252.

36. Léger L.A., Mercier D., Gadoury C., Lambert J. (1988) The multistage 20 metre shuttle run test for aerobic fitness. J. Sports Sci., 6: 93-101.

37. Lisowski P., Kantanista A., Bronikowski M. (2020) Are there any differences between first grade boys and girls in physical fitness, physical activity, BMI and sedentary behavior? Results of HCSC Study. Int. J. Environ. Res. Public Health, 17(3): 1109. DOI: 10.3390/ijerph17031109.

38. Malina R.M. (2010) Early sport specialization: roots, effectiveness, risks. Cur. Sports Med. Rep., 9(6): 364-371. DOI: $10.1249 /$ JSR.0b013e3181fe3166.

39. Mattocks C., Ness A., Leary S., Tilling K., Blair S.N., Shield J., Deere K., Saunders J., Kirkby J., Smith G.D., Wells J., Wareham N., Reilly J., Riddoch C. (2008) Use of accelerometers in a large field-based study of children: Protocols, design issues, and effects on precision. J. Phys. Act. Health, 5(Supp 1): S98-S111. DOI: 10.1123/ jpah.5.s1.s98.

40. Meredith M.D., Welk G.J. (2005) Fitnessgram/activitygram: Test administration manual. Champaign, IL: Human Kinetics.

41. Mononen K., Blomqvist M., Koski P., Kokko S. (2016) Urheilu ja seuraharrastaminen [Sports club participation]. In Kokko S. \& Mehtälä A. (eds) Lasten ja nuorten liikuntakäyttäytyminen Suomessa. Liitu-tutkimuksen tuloksia 2016. [The physical activity behaviours of children and adolescents in Finland. Results of the LIITU study], 2016. Helsinki: Publications of the National Sports Council. 27-35.

42. Mostafavifar A.M., Best T.M., Myer G.D. (2013) Early sport specialisation, does it lead to long-term problems?
Br. J. Sport Med., 47: 1060-1061. DOI: 10.1136/bjsports2012-092005.

43. Myer G.D, Jayanthi N., DiFiori J.P. Faigenbaum A.D., Kiefer A.W., Logerstedt D., Micheli L.J. (2016) Sports specialization, part II: Alternative solutions to early sport specialization in youth athletes. Sports Health: A Multidiscip Approach, 8(1). DOI: 10.1177/1941738115614811.

44. Myer G.D, Jayanthi N., Difiori J.P., Faigenbaum A.D., Kiefer A.W., Logerstedt D., Micheli L.J. (2015) Sport Specialization, part I: Does early specialization increase negative outcomes and reduce the opportunity for success in young athletes? Sports Health Multidiscip Approach, 7(5): 437-442. DOI: 10.1177/1941738115598747.

45. Patterston P., Bennington J., De La Rosa T. (2001) Psychometric properties of child- and teacherreported curl-up scores in children ages 10-12 years. Res. Q. Exerc. Sports., 72(2): 117-124. DOI: 10.1080/02701367.2001.10608941.

46. Opstoel K., Pion J., Elferink-Gemser M., Hartman E., Willemse B., Philippaerts R., Visscher C., Lenoir M. (2015) Anthropometric characteristics, physical fitness and motor coordination of 9 to 11 year old children participating in a wide range of sports. PLOS One, 10(5): e126282.

47. Robinson L.E., Stodden D.F., Barnett L.M., Lopes V.P., Logan S.W., Rodriques L.P., D’Hondt E. (2015) Motor competence and its effect on positive developmental trajectories of health. Sports Med., 45(9): 1273-1284. DOI: 10.1007/s40279-015-0351-6.

48. Saint Romain B., Mahar M.T. (2001) Norm-referenced and criterion-referenced reliability of the push-up and modified pull-up. Meas. Phys. Educ. Exerc. Sci., 5(2): 67-80. DOI: 10.1207/S15327841MPEE0502_1.

49. Salin K., Huhtiniemi M., Watt A., Hakonen, H., Jaakkola T. (2019) Differences in physical activity, sedentary time and BMI of Finnish Grade 5 students. J. Phys. Act. Health, 16(9): 765-771. DOI: 10.1123/jpah.2018-0622.

50. Stodden D.F., Goodway J.D., Langendorfer S.J., Roberton M.A., Rudisill M.E., Garcia C., Garcia L.E. (2008) A developmental perspective on the role of motor skill competence in physical activity: An emergent relationship. Quest, 60: 290-306. DOI: 10.1080/00336297.2008.10483582.

51. Ströhle A. (2009) Physical activity, exercise, depression and anxiety disorders. J. Neural. Transm., 16(6): 777. DOI: 10.1007\%252Fs00702-008-0092-x.

52. Tucker P. (2008) Physical activity levels of preschoolaged: A systematic review. Early Child Res. Q., 23(4): 547-558. DOI: 10.1016/j.ecresq.2008.08.005.

53. Vandendriessche J.B., Vandorpe B.F.R., Vayens R., Malina R.M., Lefevre J., Lenoir M., Philippaerts R.M. (2012) Variation in sport participation, fitness and motor coordination with socioeconomic status among Flemish children. Pediatr. Exerc. Sci., 24: 113-128. DOI: 10.1123/ pes.24.1.113. 
54. Vicente-Rodríguez G., Urzanqui A., Mesana M.I., Ortega F.B., Ruiz J.R., Ezquerra J., Casájus J.A., Blay G., Blay V.A., Gonzalez-Gross M., Moreno L.A. (2008) Physical fitness effect on bone mass is mediated by the independent association between lean mass and bone mass through adolescence: a cross-sectional study. J. Bone Miner. Metab., 26(3): 288-294. DOI: 10.1007/s00774-007-0818-0.

55. Wylleman P., Reints A. (2010) A lifespan perspective on the career of talented and elite athletes: Perspectives on high-intensity sports. Scand. J. Med. Sci. Sport, 20(2): 88-94. DOI: 10.1111/j.1600-0838.2010.01194.x.
Received 30.09.2020

Accepted 30.10.2020

(C) University of Physical Education, Warsaw, Poland

Acknowledgments

This work was supported by the Ministry of Education and Culture (61/626/2016). 